\title{
MiR-25-3p regulates the differentiation of intramuscular preadipocytes in goat via targeting KLF4
}

\author{
Yu Du ${ }^{1,2,3}$, Yue Zhao ${ }^{1,2}$, Yong Wang ${ }^{1,2}$, Qingyong Meng ${ }^{4}$, Jiangjiang Zhu ${ }^{1,2}$, and Yaqiu Lin ${ }^{1,2}$ \\ ${ }^{1}$ Key Laboratory of Qinghai-Tibetan Plateau Animal Genetic Resource Reservation and Utilization, \\ Ministry of Education, Southwest Minzu University, Chengdu, China \\ ${ }^{2}$ Qinghai-Tibetan Plateau Animal Genetic Resource Reservation and Utilization Key Laboratory of Sichuan \\ Province, College of Animal Science and Veterinary Medicine, Chengdu, China \\ ${ }^{3}$ Institute of Qinghai-Tibetan Plateau, Chengdu 610041, China \\ ${ }^{4}$ State Key Laboratory of Agrobiotechnology, College of Biological Sciences, \\ China Agricultural University, Beijing 100193, China
}

Correspondence: Yaqiu Lin (linyq1999@163.com)

Received: 16 August 2020 - Revised: 23 October 2020 - Accepted: 23 November 2020 - Published: 18 January 2021

\begin{abstract}
Adipocyte differentiation, which plays an important role in fat deposition, involves a complex molecular mechanism. MicroRNAs (miRNAs) are essential in this progress. Here, we showed that miR-25-3p expression had increased during goat intramuscular preadipocyte differentiation, which peaked at day 3 . Using liposome transfection and qRT-PCR techniques, we found that knocking down miR-25-3p reduced the accumulation of lipid droplets by downregulating or upregulating the expression of $L P L, P P A R \gamma, A P 2, S R E B P 1$, and $C / E B P \beta$ but upregulating the expression of KLF4. Overexpression of miR-25-3p results in the opposite. Furthermore, the dual luciferase assay showed that overexpression of miR-25-3p significantly inhibited luciferase activity of KLF4. These results showed that miR-25-3p has a binding site within the 3'-UTR of KLF4 mRNA. Together, these findings indicate that miR-25-3p is a positive regulator of intramuscular preadipocyte differentiation via targeting to KLF4 in goats.
\end{abstract}

\section{Introduction}

Intramuscular fat (IMF) is a type of fatty tissue deposited between skeletal muscle fibers and muscle bundles, which is regulated by the number and size of preadipocytes in the muscle, and it is a key factor affecting meat tenderness, flavor, and juiciness (Jiang et al., 2019; Ren, 2019). Studies have shown that multiple signaling pathways and their target genes can regulate fat deposition via regulating the process of adipocyte formation, proliferation, differentiation, and maturation (Grieco et al., 2019; Hafner et al., 2010; Son et al., 2014).

MicroRNAs are a class of endogenous single-stranded non-coding small RNAs about 18-25 nucleotides long. Studies have shown that microRNAs (miRNAs) can participate in a variety of biology pathway and cell functions, because the seed sequence of miRNAs can combine with the $3^{\prime}$ un- translated region $\left(3^{\prime}\right.$-UTR) of the target gene and regulate the expression of target gene by the way of inhibiting protein translation or degrading its mRNA (Lin et al., 2019; Zhou et al., 2013). Numerous studies have demonstrated the important role of miRNAs in regulating adipogenesis and lipid metabolism (Engin, 2017; Irani and Hussain, 2015; Zaiou et al., 2018; Qi et al., 2019; Lin et al., 2019; Acharya et al., 2019). For example, a study found that the expression of miR-425 may be controlled by PPAR $\gamma$ during the adipogenesis process of adipocytes. Overexpression of miR-425 inhibited the proliferation of 3T3-L1 precursor adipocytes but significantly accelerated cellular adipogenic differentiation (Qi et al., 2019). Furthermore, miR-130a promotes the differentiation of mouse bone marrow mesenchymal stem cells (BM$\mathrm{SCs}$ ) by negatively regulating the expression of Smurf2 (Lin et al., 2019) 
Knockout of all miR-26-encoding loci can cause adipose tissue to swell rapidly in normally fed adult mice. However, miR-26a transgenic overexpressing mice are protected from obesity induced by a high-fat diet. Interestingly, miR-26 can restrain the differentiation and adipogenesis of adipocyte progenitor cells (APC) by targeting Fbxl19 (Acharya et al., 2019).

miR-25-3p is a member of the miR-106b 25 cluster (Wu et al., 2019) and has been reported to be involved in proliferation (Feng et al., 2014), apoptosis (Zhang et al., 2012), and motility (Xiang et al., 2015). Furthermore, previous studies have shown that the miR-106b 25 cluster could regulate atherosclerosis in mice. The study found that, at 36 weeks of age, the lesion size of MiR-106b 25 and ApoE double-knockout mice was 2 times smaller than that of ApoE knockout mice (Semo et al., 2019). In addition, miR-25 can inhibit triacylglycerol synthesis and lipid accumulation in goat mammary epithelial cells by negatively regulating $P G C$ 1beta expression levels (Ma et al., 2018). These studies suggest that miR-25-3p may play an important role in regulating lipid metabolism and adipocyte differentiation.

Here, we investigated the role of miR-25-3p in adipogenesis of goat intramuscular preadipocytes and explored the underlying mechanism by identifying the involved factors. Our results show that overexpression of miR-25-3p can promote the expression level of key adipogenic regulatory genes. Then we examined the regulatory relationship between miR25-3p and its putative target gene $K L F 4$, which was demonstrated by luciferase reporter assay.

\section{Materials and methods}

\subsection{Experimental animals}

The goat intramuscular preadipocytes was obtained from the two male Jian Zhou goats (Sichuan, China) whose age was 57 days old. All experimental procedures were reviewed and approved by the Institutional Animal Care and Use Committee, Southwest Minzu University (Chengdu, Sichuan, China), and all the experiments complied with the requirements of the directory of the Ethical Treatment of Experimental Animals of China.

\subsection{Cell culture and adipogenic differentiation}

Detailed procedure for the collection and culture of intramuscular preadipocytes have previously been published $(\mathrm{Xu}$ et al., 2018). The F1 of goat intramuscular preadipocytes was cultured in DMEM/F12 (Hyclone, USA), containing $10 \%$ $(v / v)$ fetal bovine serum (FBS, Hyclone, USA), and put in a humidified incubator at $5 \% \mathrm{CO}_{2}$ and $37^{\circ} \mathrm{C}$. The $\mathrm{F} 3$ cells were seeded into 12 -well plates, and then the goat intramuscular preadipocytes reached $80 \%$ confluence and were adipogenically induced by DMEM/F12 containing $10 \%$ FBS
Table 1. RNA oligonucleotides in this article.

\begin{tabular}{ll}
\hline Name & Sequence $\left(5^{\prime}-3^{\prime}\right)$ \\
\hline miR-25-3p mimic & $\begin{array}{l}\text { CAUUGCACUUGUCUCGGUCUGA } \\
\text { AGACCGAGACAAGUGCAAUGUU }\end{array}$ \\
\hline Negative mimic & $\begin{array}{l}\text { UUCUCCGAACGUGUCACGUTT } \\
\text { ACGUGACACGUUCGGAGAATT }\end{array}$ \\
\hline miR-25-3p inhibitor & UCAGACCGAGACAAGUGCAAUG \\
\hline Negative inhibitor & CAGUACUUUUGUGUAGUACAA \\
\hline
\end{tabular}

and $50 \mu \mathrm{mol} \mathrm{L} \mathrm{L}^{-1}$ oleic acid (Shang et al., 2014). The medium was changed every two days until day 6 .

\subsection{Cell transfection}

Before transfection, miR-25-3P mimics, inhibitor and $\mathrm{NC}$ were put into centrifuge at $2000 \mathrm{rpm}$ for $10 \mathrm{~min}$, then added $250 \mu \mathrm{L}$ RNase Free $\mathrm{H}_{2} \mathrm{O}$ to dissolve to $20 \mu \mathrm{M}$, stored at $-20^{\circ} \mathrm{C}$. When the preadipocytes reached $80 \%$ of the plates, the goat intramuscular preadipocytes were transfected with Opti-MEM (Gibco-BRL Co. LTD), negative control (NC) (GenePharma, Shanghai, China), miR-25-3P mimics, and miR-25-3P inhibitor using Lipofectamine 3000 (Invitrogen, Carlsbad, USA) according to the manufacturer's instructions. After $6 \mathrm{~h}$, the original medium was replaced by fresh differentiation medium to induce preadipocyte differentiation, and cells were collected after $48 \mathrm{~h}$ for RNA extraction.

\subsection{RNA extraction and qRT-PCR}

Total RNA of cells was extracted using TRIzol (TaKaRa, Otsu, Japan) and stored at $-80^{\circ} \mathrm{C}$. Reverse transcription of mRNA was performed using the Revert Aid First Strand cDNA Synthesis Kit (TaKaRa, Otsu, Japan) according to the manufacturer's instructions. Reverse transcription reactions for miRNA were performed using Mir-X ${ }^{\mathrm{TM}}$ miRNAs First-Strand Synthesis Kit (TaKaRa, Otsu, Japan) as per the manufacturer's instructions. U6 small nucleolar RNA and ubiquitously expressed transcript (UXT) were used as an endogenous control for miRNA and mRNA, respectively. The sequences of primers used are listed in Table 1. Abundance of mRNA for each gene was measured using LineGene 9600 Plus real-time PCR detection system (Bioer, Hangzhou China). The reaction volume for real-time PCR was $20 \mu \mathrm{L}$ and consisted of $1 \mu \mathrm{L}$ cDNA, $1 \mu \mathrm{L}$ reverse and forward primers (per gene), $7 \mu \mathrm{L}$ double-distilled water, and $10 \mu \mathrm{L}$ TB Green ${ }^{\mathrm{TM}}$ Premix Ex Taq ${ }^{\mathrm{TM}}$ II (Takara, Otsu, Japan). The sequences of primers used are listed in Table 2. Relative gene expression levels were determined by the $2^{-\Delta \Delta \mathrm{Ct}}$ method (Rao et al., 2013). 
Table 2. Primers utilized in this study.

\begin{tabular}{|c|c|c|c|c|}
\hline Gene & Reference in GenBank & Primer sequence $\left(5^{\prime}-3^{\prime}\right)$ & $\operatorname{Tm}\left({ }^{\circ} \mathrm{C}\right)$ & Product size (bp) \\
\hline$P P A R \gamma$ & NM_001285658.1 & $\begin{array}{l}\text { F: AAGCGTCAGGGTTCCACTATG } \\
\text { R: GAACCTGATGGCGTTATGAGAC }\end{array}$ & 60 & 197 \\
\hline$A P 2$ & NM_001285623.1 & $\begin{array}{l}\text { F: TGAAGTCACTCCAGATGACAGG } \\
\text { R: TGACACATTCCAGCACCAGC }\end{array}$ & 58 & 143 \\
\hline$L P L$ & NM_001285607.1 & $\begin{array}{l}\text { F: TCCTGGAGTGACGGAATCTGT } \\
\text { R: GACAGCCAGTCCACCACGAT }\end{array}$ & 60 & 174 \\
\hline$C / E B P \beta$ & XM_018058020.1 & $\begin{array}{l}\text { F: CAAGAAGACGGTGGACAAGC } \\
\text { R: AACAAGTTCCGCAGGGTG }\end{array}$ & 66 & 204 \\
\hline$S R E B P 1$ & NM_001285755.1 & $\begin{array}{l}\text { F: AAGTGGTGGGCCTCTCTGA } \\
\text { R: GCAGGGGTTTCTCGGACT }\end{array}$ & 58 & 127 \\
\hline$U X T$ & XP_005700899.1 & $\begin{array}{l}\text { F: GCAAGTGGATTTGGGCTGTAAC } \\
\text { R: TGGAGTCCTTGGTGAGGTTGT }\end{array}$ & 60 & 180 \\
\hline U6 & NR_138085.1 & $\begin{array}{l}\text { F: GGAACGATACAGAGAAGATTAGC } \\
\text { R: TGGAACGCTTCACGAATTTGCG }\end{array}$ & 64 & 189 \\
\hline$K L F 4$ & KU041754.1 & $\begin{array}{l}\text { F: GTCGGTCATCAGTGTTAGCAAAGG } \\
\text { R: ACGGTGCACGAGGAGACAGTCT }\end{array}$ & 62 & 126 \\
\hline $\operatorname{miR}-25-3 p$ & MIMAT0036100 & CATTGCACTTGTCTCGGTCTGA & 61 & - \\
\hline
\end{tabular}

Note: $\mathrm{F}$ - sense primer; $\mathrm{R}$ - antisense primer.

\subsection{Oil red O staining}

As described in a previous investigation with minor modifications (Xu et al., 2019), the cells were cultured at 24-well plates and visualized by oil red $\mathrm{O}$ staining. The differentiated adipocytes were fixed with $10 \%$ formaldehyde for $30 \mathrm{~min}$ and washed twice with PBS. The fixed adipocytes were staining with oil red $\mathrm{O}$ working solution for $20 \mathrm{~min}$. After that, the cells were washed three times with PBS and photographed under a microscope.

\subsection{Luciferase reporter assay}

The $3^{\prime}$-UTR of KLF4, containing the miR-25-3p targeted site, was cloned using primers with NheI and XbaI (Thermo, MA, USA) cleavage sites. The wild-type $3^{\prime}$-UTR fragment was inserted into the corresponding site of the pmirGLO dual-luciferase vector (Promega, Madison, WI, USA). Then we co-transfected into $293 \mathrm{~T}$ cells with miR-25-3p mimics, mimic NC, pmirGLO, and pmirGLO-KLF4. Cells were harvested after transfection $48 \mathrm{~h}$, and then the dual-luciferase activity was analyzed using the Dual-Luciferase Reporter Assay System kit (Promega, Madison, WI, USA) according to the manufacturer's instructions.

\subsection{Statistical analysis}

Data are expressed as the "Means \pm SEM" of three replicates in each experiment and analyzed using GraphPad Prism
5.0 (GraphPad Inc. USA) software. A $t$ test was performed by SPSS 18 software (SPSS Inc. Chicago, IL, USA) to determine statistical differences between two groups. Comparisons between multiple groups were carried out using oneway analysis of variance. $P<0.05$ was considered statistically significant.

\section{Results}

\subsection{Expression pattern of miR-25-3p during differentiation of goat intramuscular preadipocytes}

Four databases were used to predict the possible target genes of miR-25-3p: Target Scan (http://www.targetscan.org/vert 71/, last access: 6 October 2020), miRCarta (https://mircarta. cs.uni-saarland.de, last access: 6 October 2020), miRTarBas (http://mirtarbase.mbc.nctu.edu.tw/index.html, last access: 6 October 2020), and microRNAseq (https://www. encodeproject.org/microrna/microrna-seq/, last access: 6 October 2020). We found 19 common target genes using Venny 2.1 online software. Then we selected KLF4 related to fat as the target gene (Fig. 1). The seed region of miR-25-3p is highly conserved among mammals (Fig. 2a). To investigate the regulation of miR-25-3p on adipocyte deposition, qRTPCR was used to detect the expression pattern of miR-25$3 p$ from day 0 to day 5 before adipocyte differentiation. As shown in Fig. 2b, miR-25-3p expression gradually increased during day 0 to day 3 , peaked on day 3 , and decreased af- 


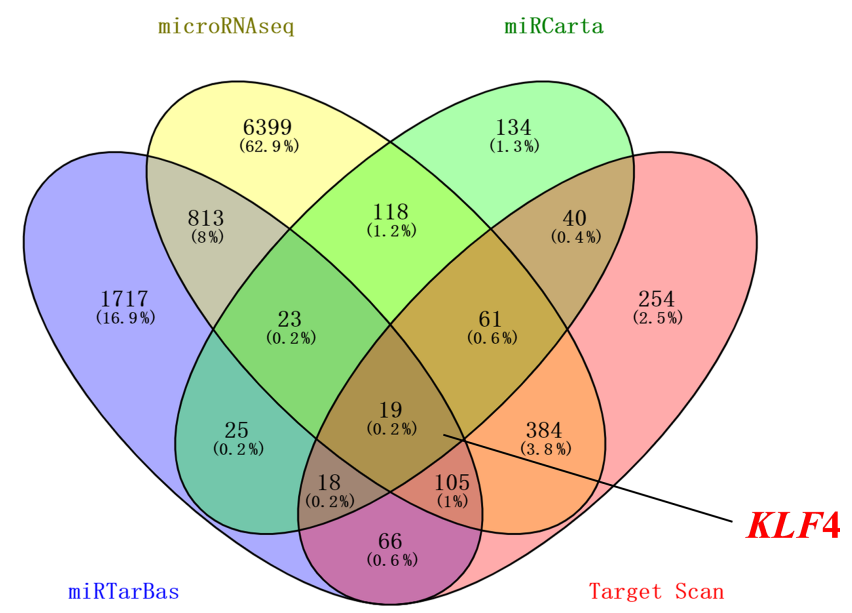

Figure 1. The target genes of miR-25-3p. Using Target Scan, miRCarta, miRTarBas, and microRNAseq found $K L F 4$ as a target gene of miR-25-3p.

miR-25-3P

(a)

$\begin{array}{ll:l}\text { Cattle: } & \text { CAUUGCACUUGUCUCG } & \text { GUCUGA } \\ \text { Monkey: } & \text { CAUUGCACUUGUCUCG } & \text { GUCUGA } \\ \text { Goat: } & \text { CAUUGCACUUGUCUCG } & \text { GUCUGA } \\ \text { Human: } & \text { CAUUGCACUUGUCUCG } & \text { GUCUGA } \\ \text { Brown Rat: } & \text { CAUUGCACUUGUCUCG } & \text { GUCUGA } \\ \text { Rat: } & \text { CAUUGCACUUGUCUCG } & \text { GUCUGA } \\ & \end{array}$

(b)

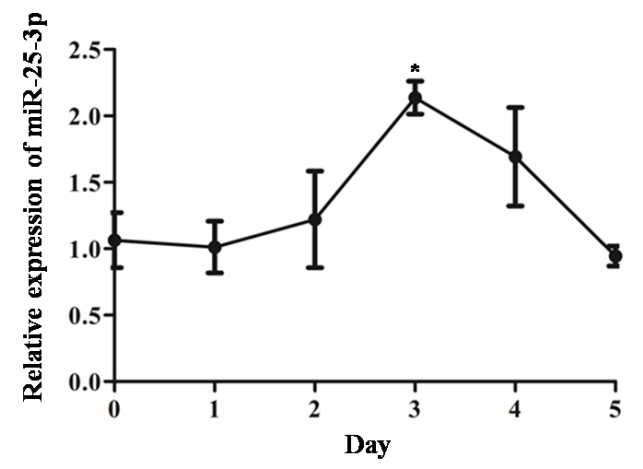

Figure 2. The relative expression levels of miR-25-3p during differentiation of goat intramuscular preadipocytes. (a) Mature miR-25$3 p$ seed region was highly conserved among mammals. (b) miR-25$3 p$ expression pattern during differentiation of goat preadipocytes.

ter that. These results indicated that miR-25-3p may play an important role during goat intramuscular adipocyte differentiation.

\subsection{Knockdown miR-25-3p inhibits goat preadipocyte differentiation}

To investigate the role of miR-25-3p in cell differentiation, goat intramuscular preadipocytes were transfected with miR- 25-3p mimics or miR-25-3p inhibitor during the differentiation period. The qRT-PCR technique was used to determine the transfection efficiency of miR-25-3p after $48 \mathrm{~h}$. The results showed that the expression levels of miR-25-3p were significantly increased upon miR-25-3p mimic transfection and decrease in response to miR-25-3p inhibitor transduction compared with the NC group $(P<0.01$; Fig. 3a). The oil red staining showed that knocking down the expression of miR-25-3p significantly decreased the formation of lipid droplets (Fig. 3b). In contrast, overexpression of miR-25-3p visibly increased lipid accumulation. These results suggested that miR-25-3p can promote goat intramuscular adipogenesis. To further investigate the potential molecular mechanism of miR-25-3p in goat intramuscular preadipocytes, we detected the expression of key adipogenic regulatory genes in adipocytes. Compared with the negative control, after knocking down miR-25-3p in goat intramuscular preadipocytes, the mRNA expression levels of lipoprotein lipase $(L P L)$, peroxisome proliferator-activated receptor gamma $(P P A R \gamma)$, adipocyte fatty acid-binding protein $(A P 2)$, sterol-regulatory element-binding proteins (SREBPI), and CCAAT/enhancerbinding protein $(C / E B P \beta)$ were significantly reduced. However, the expression of the target gene $K L F 4$ was significantly increased (Fig. 4a). As expected, overexpression of miR-25$3 p$ showed the opposite result (Fig. 4b). These results indicated that miR-25-3p may play a positive regulatory role during the differentiation of goat intramuscular preadipocytes.

\subsection{KLF4 as a target gene of miR-25-3p}

The above research proves that miR-25-3p plays an important role in the differentiation of adipocytes. To further explore its molecular mechanism, we used luciferase reporter assay to verify the relationship between KLF4 and miR-25$3 p$ (Fig. 5a). The result showed that when miR-25-3p was overexpressed, the mRNA expression of KLF4 was significantly inhibited (Fig. 5b). As expected, miR-25-3p mimics and KLF4 3'-UTR dual-luciferase reporter vectors cotransfected into $293 \mathrm{~T}$ cells significantly reduced the activity of the pmirGLO-KLF4-3'-UTR reporter gene, suggesting that miR-25-3p can target the $3^{\prime}-$ UTR of KLF4 (Fig. 5c).

\section{Discussion}

The important role of fat is to store energy and maintain metabolic stability. According to the location of fat deposition, it can be divided into four categories: subcutaneous fat, intermuscular fat, intramuscular fat, and visceral fat. Among them, intramuscular fat deposition is of great significance to meat flavor, nutrition, and taste (Cui et al., 2016; Poleti et al., 2018a; Wood et al., 2008). In addition, intramuscular fat cells can gradually accumulate through the proliferation and differentiation to form the marble pattern in meat (Poleti et al., 2018b; Zhao et al., 2019). In recent years, miRNAs have become a hot spot for studying the processes of fat differenti- 
(a)

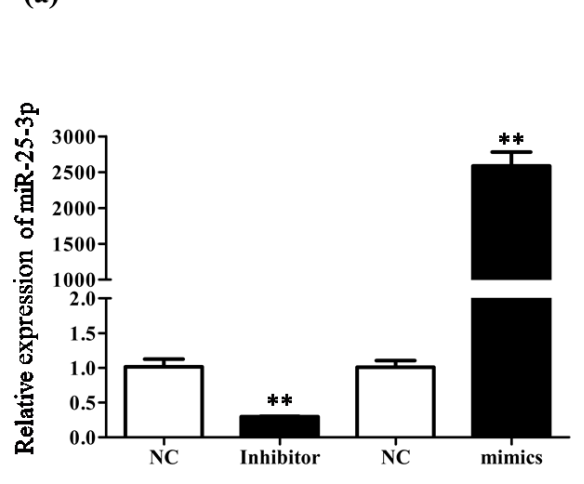

(b)

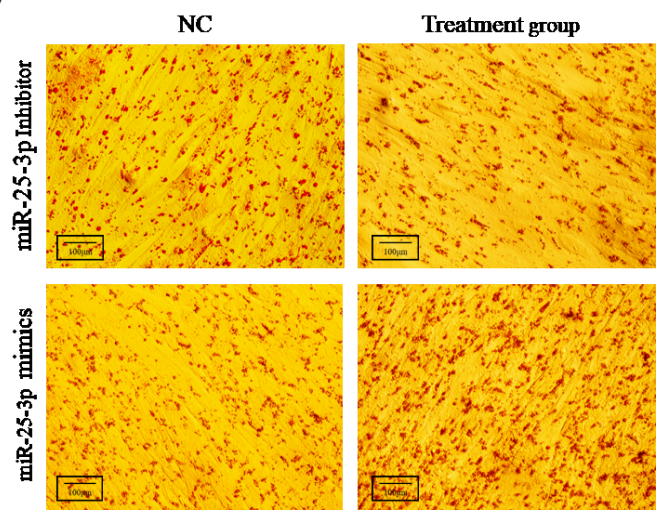

Figure 3. Knockdown miR-25-3p decreased the formation of lipid droplets in goat preadipocyte differentiation. (a) The transfection efficiency of miR-25-3p mimics and miR-25-3p inhibitor was detected by qRT-PCR, compared with the negative control. (b) After $48 \mathrm{~h}$ of preadipocyte differentiation, cells were fixed and stained with Oil Red O.

(a)

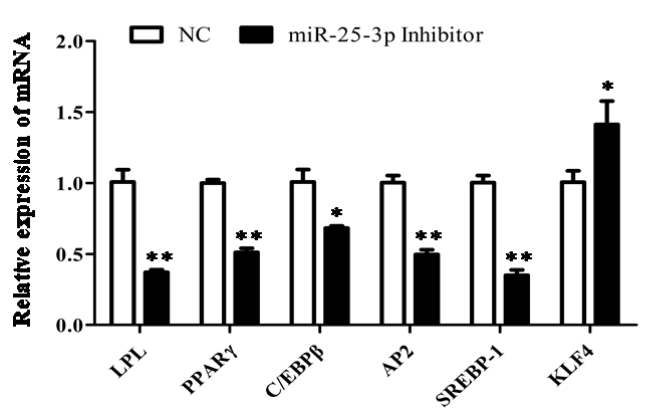

(b)

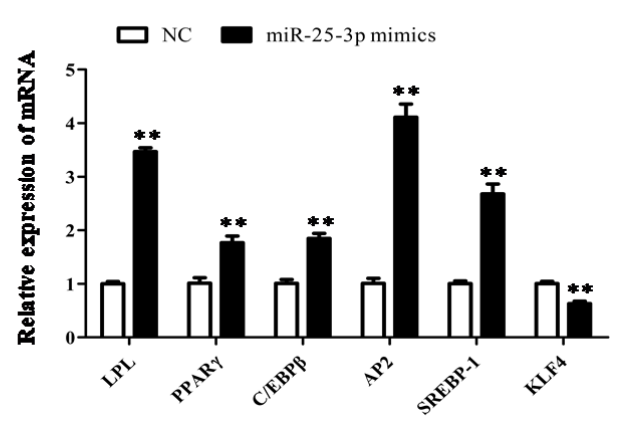

Figure 4. Overexpression of miR-25-3p promotes goat intramuscular differentiation. (a) The mRNA expression levels of key adipogenic regulatory genes were detected after transfected miR-25-3p inhibitor in goat intramuscular preadipocytes. (b) The mRNA expression levels of key adipogenic regulatory genes were detected after transfected miR-25-3p mimics in goat intramuscular preadipocytes.

ation and lipid metabolism. For example, miR-142 and miR144 can target FoxOl and inhibit its expression level in sheep precursor adipocytes while promoting the differentiation of adipocytes via the negative regulation of PPAR $\gamma$ by $F O x O 1$ (Zhao, 2018). In addition, miR-331-3p can inhibit the proliferation of porcine precursor adipocytes. Overexpression of miR-331-3p can regulate the expression of dihydrolipamide S-succinyltransferase (DLST) to regulate fatty acid accumulation in the citrate pyruvate cycle (Chen et al., 2019). However, the molecular mechanism underlying the role of miR25-3p in lipogenesis is not fully understood.

In this experiment, we investigated the role of miR-25$3 p$ in regulating goat intramuscular preadipocyte differentiation. We found that the expression of miR-25-3p was gradually increased in the early phase and then decreased. We also showed that overexpression of miR-25-3p promoted, whereas downregulation of miR-25-3p suppressed goat intramuscular preadipocyte differentiation and lipid accumulation. This suggests that miR-25-3p plays a positive role in intramuscular preadipocyte differentiation in goats. Pre- vious research has shown that miR-25 suppressed 3T3-L1 adipogenesis by targeting $K L F 4$ and $C / E B P \alpha$ (Liang et al., 2015). Moreover, the latest research demonstrated that exosomal miR-25-3p could promotes vascular permeability and angiogenesis in mouse vascular endothelial cells by targeting and inhibiting the expression level of KLF4 (Zeng et al., 2018). We think that this could be a difference between from different species or organs. Noteworthy is the fact that the expression of key adipogenic genes in our study also had dramatic changes.

$L P L$ is a rate-limiting enzyme that can be widely distributed in adipose tissue. In brown adipose tissue, $L P L$ is related to thermogenesis. In white adipose tissue, the increase in $L P L$ activity can help lipid storage (Nimonkar et al., 2020; Pérez-Torres et al., 2019; Ruppert and Kersten, 2020). PPAR $\gamma$ is a member of the nuclear receptor family and a necessary transcription factor for adipogenesis. The functions of $P P A R \gamma$ are to promote the expression of genes involved in adipogenesis and maintaining mature adipocytes (Jeon et al., 2020). Furthermore, in goat mammary epithelial 
(a)

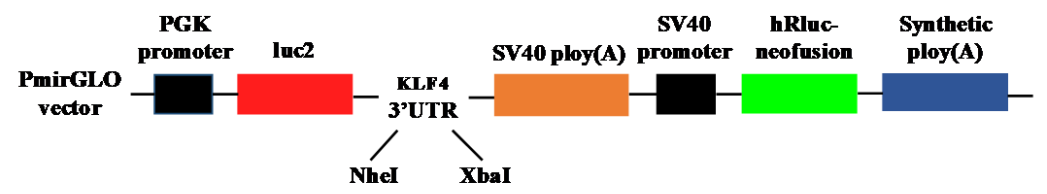

KLF43'UTR 5'-TCAGACAATACGTGACACCAAA -3'

IIIIII

miR-25-3p 3'-AGUCUGGCUCUGUUCACGUUAC -5'

(b)

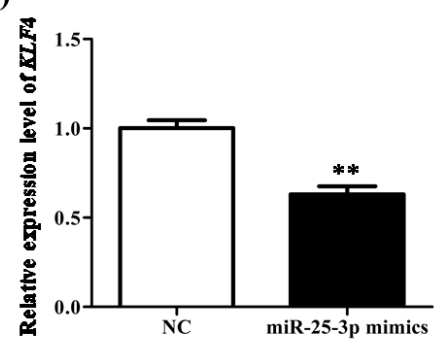

(c)

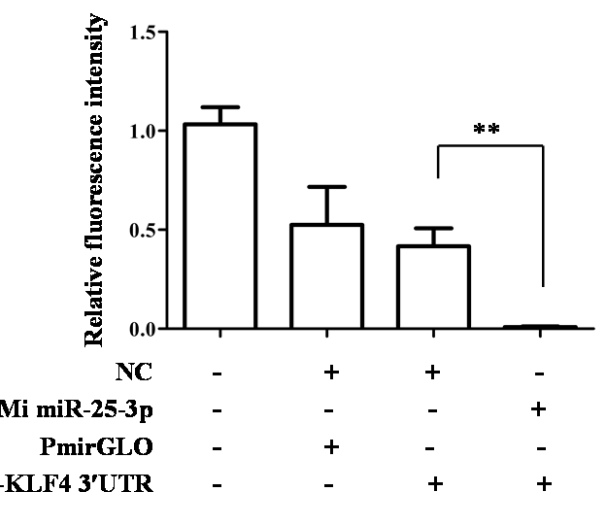

Figure 5. miR-25-3p can target $3^{\prime}$-UTR of KLF4. (a) Schematic diagram of pmirGLO dual luciferase and the interaction between miR25-3p and KLF4. (b) The mRNA expression level of KLF4 after miR-25-3p overexpression. (c) $K L F 43^{\prime}$-UTR dual luciferase vector was co-transfected with miR-25-3p mimics and negative control.

cells PPAR $\gamma$ could significantly up-regulate the expression of genes that are related to synthesis and secretion of promoting fat deposition, such as LPL, FASN, ACACA, PLIN3, FABP3, PLIN2, and SREBF1 (Shi et al., 2013). AP2 is a fatty acid binding protein that promotes the hydrolysis and transport of lipids in the cytoplasm (Zhang et al., 2019). Studies have shown that overexpression of KLF9 in chicken precursor adipocytes can inhibit the accumulation of triglycerides by down-regulating AP2 (Sun et al., 2019). SREBP1 can regulate the expression of genes related to fatty acid synthesis. Knockout SREBPI in human liver cancer cells can inhibit the synthesis of triglycerides and prevent the expression levels of fatty acid synthesis genes, such as $A C L Y, A C A C A$, and FASN (Edwards et al., 2000; Moon et al., 2001; Yang et al., 2019). In our study, overexpression of miR-25-3p significantly promoted the mRNA expression levels of $L P L, P P A R \gamma, A P 2$, $S R E B P 1$, and $C / E B P \beta$. Together, these results further suggest that the fat-promoting effect of miR-25-3p can be attributed to inhibition of the key adipogenic genes during goat intramuscular preadipocyte adipogenesis.

To screen the targets of miR-25-3p and the possible binding sites between miR-25-3p and its target, using Target Scan, miRCarta, miRTarBas, and microRNAseq target prediction packages, we found that KLF4 $3^{\prime}$-UTR can efficiently bind to the miR-25-3p seed region, which is highly conserved among mammals. $K L F 4$ is a member of $K L F \mathrm{~s}$, and a growing number of studies have confirmed the role of $K L F \mathrm{~s}$ in regulating adipocyte differentiation (Lee et al., 2016; Ma et al., 2020). As expected, the luciferase assay showed that over- expression of miR-25-3p significantly reduced luciferase activity of $K L F 4$, which was consistent with the mechanism of miRNAs targeting mRNA in goat intramuscular adipocytes. Previous studies have shown that overexpression of KLF4 can inhibit the accumulation of lipid droplets in goat intramuscular preadipocytes (Lin, 2018). In addition, in mouse stromal vascular cells and both subcutaneous and visceral human fat, an adenosine receptor-Krüppel-like factor 4 protein axis inhibits adipogenesis (Anna et al., 2014). The qRT-PCR result in our study showed that overexpression of miR-25-3p inhibited the expression of KLF4 exceedingly.

Taken together, these results further suggest that miR25-3p plays a positive regulation in goat intramuscular preadipocyte via targeting $K L F 4$ and inhibiting its expression.

\section{Conclusions}

We demonstrated that miR-25-3p positively regulates the differentiation of goat intramuscular preadipocytes. Furthermore, we found that miR-25-3p promotes preadipocyte differentiation by regulating the expression of key adipogenic genes and binding to the $3^{\prime}$-UTR of KLF4 and thereby inhibiting KLF4 transcription.

Data availability. The original data are available upon request to the corresponding author. 
Author contributions. YW, JZ, and YL conceived and designed the experiments. YD and YZ performed the experiments. QM, JZ, and YL analyzed the data. YD wrote the manuscript.

Competing interests. The authors declare that they have no conflict of interest.

Acknowledgements. We would like to thank the College of Animal Science and Veterinary Medicine for supplying the equipment used in the experiment. We also thank Sichuan Jianyang Big Brother Dairy Co., Ltd. for providing experimental animals.

Financial support. This research has been supported by the National Natural Science Foundation of China (grant no. 31672395), the National Key R\&D Program of China (grant no. 2018YFD0502002), the Applied Basic Research Program of Sichuan Province (grant no. 2018JY0036), and the Fundamental Research Funds for the Central Universities (grant no. 2020PTJS15004).

Review statement. This paper was edited by Steffen Maak and reviewed by three anonymous referees.

\section{References}

Acharya, A., Berry, D. C., Zhang, H., Jiang, Y., Jones, B. T., Hammer, R. E., Graff, J. M., and Mendell, J. T.: MiR-26 suppresses adipocyte progenitor differentiation and fat production by targeting Fbxl19, Gene. Dev., 33, 1367-1380, https://doi.org/10.1101/gad.328955.119, 2019.

Anna, E., Shannon, H. C., Hillary J. C., Melissa, F., Noyan, G., and Katya, R.: An adenosine receptor-Krüppel-like factor 4 protein axis inhibits adipogenesis, J. Biol. Chem., 289, 21071-21081, https://doi.org/10.1074/jbc.M114.566406, 2014.

Chen, T., Cui, J., Ma, L., Zeng, Y., and Chen, W.: The Effect of MicroRNA-331-3p on Preadipocytes Proliferation and Differentiation and Fatty Acid Accumulation in Laiwu Pigs, Biomed. Res. Int., 2019, 9287804, https://doi.org/10.1155/2019/9287804, 2019.

Cui, J., Chen, W., Liu, J., Xu, T., and Zeng, Y.: Study on quantitative expression of PPAR $\gamma$ and ADRP in muscle and its association with intramuscular fat deposition of pig, SpringerPlus, 5, 1501, https://doi.org/10.1186/s40064-016-3187-0, 2016.

Edwards, P. A., Tabor, D., Kast, H. R., and Venkateswaran, A.: Regulation of gene expression by SREBP and SCAP, Biochim Biophys Acta, 1529, 103-113, https://doi.org/10.1016/s13881981(00)00140-2, 2000.

Engin, A. B.: MicroRNA and Adipogenesis, Adv. Exp. Med. Biol., 960, 489-509, https://doi.org/10.1007/978-3-319-483825_21, 2017.

Feng, S. J., Pan, W. J., Jin, Y., and Zheng, J. H.: MiR-25 promotes ovarian cancer proliferation and motility by targeting LATS2, Tumour Biol., 35, 12339-12344, https://doi.org/10.1007/s13277014-2546-0, 2014.
Grieco, G. E., Brusco, N., Licata, G., Nigi, L., Formichi, C., Dotta, F., and Sebastiani, G.: Targeting microRNAs as a Therapeutic Strategy to Reduce Oxidative Stress in Diabetes, Int. J. Mol. Sci., 20, 6358, https://doi.org/10.3390/ijms20246358, 2019.

Hafner, M., Landthaler, M., Burger, L., Khorshid, M., Hausser, J., Berninger, P., Rothballer, A., Ascano, M., Jungkamp, A.-C., Munschauer, M., Ulrich, A., Wardle, G. S., Dewell, S., Zavolan, M., and Tuschl, T. Transcriptome-wide identification of RNAbinding protein and microRNA target sites by PAR-CLIP, Cell., 141, 129-141, https://doi.org/10.1016/j.cell.2010.03.009, 2010.

Irani, S. and Hussain, M. M.: Role of microRNA-30c in lipid metabolism, adipogenesis, cardiac remodeling and cancer, Curr. Opin. Lipidol., 26, 139-146, https://doi.org/10.1097/MOL.0000000000000162, 2015.

Jeon, Y. G., Lee, J. H., Ji, Y., Sohn, J. H., Lee, D., Kim, D. W., Yoon, S. G., Shin, K. C., Park, J., Seong, J. K., Cho, J.-Y., Choe, S. S., and Kim, J. B.: RNF20 Functions as a Transcriptional Coactivator for PPAR $\gamma$ by Promoting NCoR1 Degradation in Adipocytes, Diabetes, 69, 20-34, https://doi.org/10.2337/db19-0508, 2020.

Jiang, Q., Sun, B., Liu, Q., Cai, M., Wu, R., Wang, F., Yao, Y., Wang, Y., and Wang, X.: MTCH2 promotes adipogenesis in intramuscular preadipocytes via an m6AYTHDF1-dependent mechanism, FASEB J., 33, 2971-2981, https://doi.org/10.1096/fj.201801393RRR, 2019.

Lee, D. S., Choi, H., Han, B. S., Kim, W. K., Lee, S. C., Oh, K.-J., and Bae, K.-H.: C-Jun regulates adipocyte differentiation via the KLF15-mediated mode, Biochem. Biophys. Res. Commun., 469, 552-558, https://doi.org/10.1016/j.bbrc.2015.12.035, 2016.

Liang, W. C., Wang, Y., Liang, P. P., Pan, X. Q., Fu, W. M., Yeung, V. S. Y., Lu, Y. F., Wan, D. C. C., Tsui, S. K. W., Tsang, S. Y., Ma, W. B., Zhang, J. F., and Waye, M. M. Y.: MiR-25 suppresses 3T3$\mathrm{L} 1$ adipogenesis by directly targeting KLF4 and $\mathrm{C} / \mathrm{EBP} \alpha$, J. Cell Biochem., 116, 2658-2666, https://doi.org/10.1002/jcb.25214, 2015.

Lin, S.: Regulation of KLF4 on intramuscular preadipocyte differentiation in goat, Southwest Minzu University, available at: https://kns.cnki.net/kns8?dbcode=CDMD (last access: 7 January 2021), 2018.

Lin, Z., He, H., Wang, M., and Liang, J.: MicroRNA-130a controls bone marrow mesenchymal stem cell differentiation towards the osteoblastic and adipogenic fate, Cell Prolif., 52, e12688, https://doi.org/10.1111/cpr.12688, 2019.

Ma, C., Xia, R., Yang, S., Liu, L., Zhang, J., Feng, K., Shang, Y., Qu, J., Li, L., Chen, N., Xu, S., Zhang, W., Mao, J., Han, J., Chen, Y., Yang, X., Duan, Y., and Fan, G.: Formononetin attenuates atherosclerosis via regulating interaction between KLF4 and SRA in apoE-/-mice, Theranostics, 10, 1090-1106, https://doi.org/10.7150/thno.38115, 2020.

Ma, L., Qiu, H., Chen, Z., Li, L., Zeng, Y., Luo, J., and Gou, D.: MiR-25 modulates triacylglycerol and lipid accumulation in goat mammary epithelial cells by repressing PGC-1beta, J. Anim. Sci. Biotechnol., 9, 48, https://doi.org/10.1186/s40104-018-0262-0, 2018.

Moon, Y. A., Shah, N. A., Mohapatra, S., Warrington, J. A., and Horton, J. D.: Identification of a mammalian long chain fatty acyl elongase regulated by sterol regulatory element-binding proteins, J. Biol. Chem., 276, 45358-45366, https://doi.org/10.1074/jbc.M108413200, 2001. 
Nimonkar, A. V., Weldon, S., Godbout, K., Panza, D., Hanrahan, S., Cubbon, R., Xu, F., Trauger, J. W., Gao, J., and Voznesensky, A.: A lipoprotein lipase-GPI-anchored highdensity lipoprotein-binding protein 1 fusion lowers triglycerides in mice: Implications for managing familial chylomicronemia syndrome, J. Biol. Chem., 295, 2900-2912, https://doi.org/10.1074/jbc.RA119.011079, 2020.

Pérez-Torres, I., Gutiérrez-Alvarez, Y., Guarner-Lans, V., Díaz-Díaz, E., Manzano Pech, L., and Caballero-Chacón, S. D. C.: Intra-Abdominal Fat Adipocyte Hypertrophy through a Progressive Alteration of Lipolysis and Lipogenesis in Metabolic Syndrome Rats, Nutrients, 11, 1529, https://doi.org/10.3390/nu11071529, 2019.

Poleti, M. D., Regitano, L. C. A., Souza, G. H. M. F., Cesar, A. S. M., Simas, R. C., Silva-Vignato, B., Oliveira, G. B., Andrade, S. C. S., Cameron, L. C., and Coutinho, L. L.: Longissimus dorsi muscle label-free quantitative proteomic reveals biological mechanisms associated with intramuscular fat deposition, J Proteomics., 179, 30-41, https://doi.org/10.1016/j.jprot.2018.02.028, 2018a.

Poleti, M. D., Regitano, L. C. A., Souza, G. H. M. F., Cesar, A. S. M., Simas, R. C., Silva-Vignato, B., Oliveira, G. B., Andrade, S. C. S., Cameron, L. C., and Coutinho, L. L.: Data from proteomic analysis of bovine Longissimus dorsi muscle associated with intramuscular fat content, Data Brief., 19, 1314-1317, https://doi.org/10.1016/j.dib.2018.06.004, 2018b.

Qi, R., Wang, J., Wang, Q., Qiu, X., Yang, F., Liu, Z., and Huang, J.: MicroRNA-425 controls lipogenesis and lipolysis in adipocytes, BBA-Mol. Cell Biol. L., 1864, 744-755, https://doi.org/10.1016/j.bbalip.2019.02.007, 2019.

Rao, X., Huang, X., Zhou, Z., and Lin, X.: An improvement of the $2^{-\Delta \Delta \mathrm{CT}}$ method for quantitative real-time polymerase chain reaction data analysis, Biostat Bioinforma Biomath., 3, 71-85, 2013.

Ren, L.: Biological Function Studies of Candidate Genes S100A10 and Bta-miR-210 Related to Intramuscular Fat Deposition in Cattle, Chinese Academy of Agricultural Sciences, available at: https://kns.cnki.net/kns8?dbcode=CDMD (last access: 7 January 2021), 2019.

Ruppert, P. M. M. and Kersten, S.: A lipase fusion feasts on fat, J. Biol. Chem., 295, 2913-2914, https://doi.org/10.1074/jbc.H120.012744, 2020.

Semo, J., Chernin, G., Jonas, M., Shimoni, S., and George, J.: Deletion of the Mir-106b 25 MicroRNA cluster attenuates atherosclerosis in Apolipoprotein E knockout mice, Lipids Health Dis., 18, 208, https://doi.org/10.1186/s12944-019-11558, 2019.

Shang, Z. C., Guo, L., Wang, N., Shi, H., Wang, Y. X., and $\mathrm{Li}, \mathrm{H}$.: Oleate promotes differentiation of chicken primary preadipocytes in vitro, Biosci. Rep., 34, 00093, https://doi.org/10.1042/BSR20130120, 2014.

Shi, H., Luo, J., Zhu, J., Li, J., Sun, Y., Lin, X., Zhang, L., Yao, D., and Shi, H.: PPAR $\gamma$ Regulates Genes Involved in Triacylglycerol Synthesis and Secretion in Mammary Gland Epithelial Cells of Dairy Goats, PPAR Res., 2013, 310948, https://doi.org/10.1155/2013/310948, 2013.
Son, Y. H., Ka, S., Kim, A. Y., and Kim, J. B.: Regulation of Adipocyte Differentiation via MicroRNAs. Endocrinol Metab (Seoul), 29, 122-135, https://doi.org/10.3803/EnM.2014.29.2.122, 2014.

Sun, G. R., Zhang, M., Sun, J. W., Li, F., Ma, X. F., Li, W. T., Han, R. L., Li, Z. J., Jiang, R. R., Li, G. X., Yan, F. B., and Kang, X. T.: Krüppel-like factor KLF9 inhibits chicken intramuscular preadipocyte differentiation, Brit. Poultry Sci., 60, 790-797, https://doi.org/10.1080/00071668.2019.1657229, 2019.

Wood, J. D., Enser, M., Fisher, A. V., Nute, G. R., Sheard, P. R., Richardson, R. I., Hughes, S. I., and Whittington, F. M. Fat deposition, fatty acid composition and meat quality: A review, Meat Sci., 78, 343-358, https://doi.org/10.1016/j.meatsci.2007.07.019, 2008.

Wu, T., Hu, H., Zhang, T., Jiang, L., Li, X., Liu, S., Zheng, C., Yan, G., Chen, W., Ning, Y., Li, Y., and Lu, Z. MiR25 Promotes Cell Proliferation, Migration, and Invasion of Non-Small-Cell Lung Cancer by Targeting the LATS2/YAP Signaling Pathway, Oxid Med Cell Longev., 2019, 9719723, https://doi.org/10.1155/2019/9719723, 2019.

Xiang, J., Hang, J. B., Che, J. M., and Li, H. C.: MiR-25 is upregulated in non-small cell lung cancer and promotes cell proliferation and motility by targeting FBXW7, Int. J. Clin. Exp. Pathol., 8, 9147-9153, 2015.

Xu, Q., Lin, S., Li, Q., Lin, Y., Xiong, Y., Zhu, J., and Wang, Y.: Fibroblast growth factor 21 regulates lipid accumulation and adipogenesis in goat intramuscular adipocyte, Anim Biotechnol., 27, 1-9, https://doi.org/10.1080/10495398.2019.1691010, 2019.

Xu, Q., Lin, S., Wang, Y., Zhu, J., and Lin, Y.: Fibroblast growth factor 10 (FGF10) promotes the adipogenesis of intramuscular preadipocytes in goat, Mol. Biol. Rep., 45, 1881-1888, https://doi.org/10.1007/s11033-018-4334-1, 2018.

Yang, N., Li, C., Li, H., Liu, M., Cai, X., Cao, F., Feng, Y., Li, M., and Wang, X.: Emodin Induced SREBP1Dependent and SREBP1-Independent Apoptosis in Hepatocellular Carcinoma Cells, Front Pharmacol., 10, 709, https://doi.org/10.3389/fphar.2019.00709, 2019.

Zaiou, M., El Amri, H., and Bakillah, A.: The clinical potential of adipogenesis and obesity-related microRNAs, Nutr. Metab. Cardiovasc. Dis., 28, 91-111, https://doi.org/10.1016/j.numecd.2017.10.015, 2018.

Zeng, Z., Li, Y., Pan, Y., Lan, X., Song, F., Sun, J., Zhou, K., Liu, X., Ren, X., Wang, F., Hu, J., Zhu, X., Yang, W., Liao, W., Li, G., Ding, Y., and Liang, L.: Cancer-derived exosomal miR-25$3 p$ promotes pre-metastatic niche formation by inducing vascular permeability and angiogenesis, Nat. Commun., 9, 5395, https://doi.org/10.1038/s41467-018-07810-w, 2018.

Zhang, H. Y., Zuo, Z., Lu, X., Wang, H. Y., and Zhu, Z. L.: MiR-25 regulates apoptosis by targeting Bim in human ovarian cancer, Oncol Rep., 27, 594-598, https://doi.org/10.3892/or.2011.1530, 2012.

Zhang, Y., Zhou, L., Zhang, Z., Xu, Q., Han, X., Zhao, Y., Song, X., Zhao, T., and Ye, L.: Effects of di (2-ethylhexyl) phthalate and high-fat diet on lipid metabolism in rats by JAK2/STAT5, Environ. Sci. Pollut. R. Int., 27, 3837-3848, https://doi.org/10.1007/s11356-019-06599-5, 2019. 
Zhao, X., Chen, S., Tan, Z., Wang, Y., Zhang, F., Yang, T., Liu, Y., Ao, H., Xing, K., and Wang, C.: Transcriptome Analysis of Landrace Pig Subcutaneous Preadipocytes during Adipogenic Differentiation, Genes (Basel), 10, 552, https://doi.org/10.3390/genes10070552, 2019.

Zhao, Y.: Study on miR-142 and miR-144 Down-Regulation Contributions to Differentiation of Ovine Rreadipocytes by Targeting FoxO1 Gene, Shanxi Agricultural University, available at: https://kns.cnki.net/kns8?dbcode=CDMD (last access: 7 January 2021), 2018.
Zhou, P., Xu, W., Peng, X., Luo, Z., Xing, Q., Chen, X., Hou, C., Liang, W., Zhou, J., Wu, X., Songyang, Z., and Jiang, S.: Largescale screens of miRNA-mRNA interactions unveiled that the $3^{\prime}$ UTR of a gene is targeted by multiple miRNAs, PloS One, 8 , e68204, https://doi.org/10.1371/journal.pone.0068204, 2013. 